\title{
Educador e projeto pedagógico no território da crença
}

\author{
Márcio Donizetti Rocha ${ }^{1}$
}

\begin{abstract}
Resumo
Este trabalho é uma reflexão acerca das implicações observadas no processo de formação do educador em sua relação com o projeto pedagógico de uma rede de ensino confessional chamada Filhas de Jesus. Foram analisadas as tais implicações, em um movimento com assumido propósito de inovação curricular, que se consolida na dinâmica de poder, considerada como prática de colonização exercida sobre um território fundamental para a definição do horizonte de convívio humano atual. Para o desenvolvimento deste estudo, foi empreendida uma revisão dos documentos: Declaração Mundial sobre Educação para Todos: em Jomtien (1990), Nova Dellhi (1993), Dakar (2000) e o Nosso Modo Próprio de Educar, a partir do método cartográfico. Observou-se, assim, o quanto a escola e a educação se encontram sob a captura de uma lógica de colonização do território da crença, presente no modelo capitalista neoliberal.
\end{abstract}

Palavras-chave: Projeto Pedagógico; Processo Educacional; Escola e Comunidade.

\section{Educator and pedagogical project in the territory of the belief}

\section{Abstract}

This paper aims to reflect on the implications observed in the training process of the educator in his/her relation with the pedagogical project. These implications were analyzed based on an international movement with clear purpose of curricular innovation, which is consolidated in the dynamics of power, considered as a practice of colonization exercised over a fundamental territory to the definition of the horizon of the current human interaction. For the development of this study, a review of the documents was undertaken: World Declaration on Education for All: in Jomtien (1990), Nova Dellhi (1993), Dakar (2000) and Our Own Way to Educate, using the cartography method. It was thus observed how school and education are under the capture of a logic of colonization of the territory of the belief, present in the neoliberal capitalist model.

Keywords: Pedagogical Project; Educational Process; School and Community.

\section{Introdução}

O tema deste trabalho está fortemente relacionado aos tipos ideológicos aos quais encontramos no campo educacional, de modo que a delimitação de seu objeto é desenvolvida na referida prática escolar. A prática pedagógica é um terreno de onde nascem diversas interrogações, mas não cria uma obrigação de fronteiras para o percurso escolhido, pois o nosso exercício de interrogar transcende uma prática individual específica. A constituição de nosso

\footnotetext{
${ }^{1}$ Professor na rede Filhas de Jesus. Campinas. Endereço Eletrônico: marcionews@uol.com.br

Periódico Horizontes - USF - Itatiba, SP-Brasil - e019006
} 
objeto de estudo se faz na tensão entre uma experiência que colabora para a sua delimitação e uma inquietação que nos força para transcender fronteiras, de modo que temos consciência de que constituímos um território que está constantemente tensionado. Este é o primeiro campo de mediação em que se situa o nosso objeto de estudo.

O objetivo deste trabalho foi desenvolver uma reflexão acerca das implicações observadas no processo de formação do educador em sua relação com o projeto pedagógico ao qual a instituição assume sua ideologia. Com isso, fizemos as extrapolações necessárias, movidos pelas exigências do tema, de modo que as questões oriundas desta tese nasceram, precisamente, do ponto de cruzamento daquilo que é chamado por uma rede de escola como "o nosso modo próprio de educar" e dos sentidos produzidos nos subterrâneos de um movimento internacional de reforma curricular. Este é o segundo campo de mediação no qual se situa o nosso objeto de estudo.

O campo ao qual iremos estudar é constituído por uma rede de ensino chamada de Filhas de Jesus que está presente em mais de dezoito países e que utiliza um documento chamado "NMPE - Nosso Modo Próprio de Educar" que é utilizado como referência em todos os colégios e obras da mesma congregação que por sua vez, está no Brasil desde 1911 para desenvolver, inicialmente, a educação feminina. Alguns estudiosos como Bittencourt (2017), Arduini (2017), Leonardi (2017), Brito (2017), Bonato (2017), Custódio (2017), Neris \& Seidl (2017), Accyoli (2017), Colombo (2017) também desenvolvem trabalhos relacionando educação com a igreja católica no Brasil constando, portanto, a importância da temática ao qual também desenvolvemos nosso trabalho.

Isso porque, a Proclamação da República do Brasil, ocorrida no ano de 1889, pode ser mencionada como um fato importante da nossa história devido aos seus desdobramentos no campo das relações entre a Igreja Católica e o Estado. Encerra-se, neste ato político, o Regime do Padroado, o qual consistiu em uma espécie de separação da Igreja e do Estado, o qual fora instituído por meio de termos jurídicos, mesmo sabendo-se que seus efeitos no campo da cultura têm outras dimensões. Após essa ruptura, foram iniciadas novas modalidades de administração 
das esferas sociais e religiosas, fazendo com que as duas instituições passassem, obrigatoriamente, por uma reestruturação.

A ideia da separação entre as referidas instituições precisou ser tomada com cautela justamente pelo fato de considerarmos, aqui, a materialidade de uma cultura. Essa forma de separação, configurada por um gesto de natureza jurídica, fez a Igreja Católica deixar de ser uma espécie de departamento do Estado, de modo que seus funcionários deixaram de pertencer ao campo da oferta de serviços públicos. Os cultos católicos bem como outros rituais religiosos não são mais oferecidos por "funcionários" pagos pelo Estado, tal como se configurava no Regime do Padroado. Tais medidas desafiaram as instituições em busca de um esforço de invenção administrativa, mesmo sabendo que uma ruptura de fato não ocorre somente por força de um decreto legal. A partir do referido episódio, poderíamos esperar uma Igreja com atuação independente, mas os vínculos tecidos no percurso dos anos da colonização fizeram com que qualquer forma de ruptura fosse tratada de forma relativa em seus diversos aspectos.

Essa ruptura que se deu de forma relativa no acerto das relações entre a Igreja e o Estado, entre o Catolicismo e a colonização portuguesa em nossas terras, acentuou o foco sobre a materialidade da cultura, com a qual lidamos em seu âmbito de composição com uma tradição. A força de sua eficácia pode estar posta, justamente, nessa materialidade de conformação da existência de um povo em um percurso de séculos. A relatividade observada na abordagem dos fatos políticos no Brasil impõe cautela em qualquer esforço de interpretação das marcas de inovação.

Para a Igreja se reorganizar, foi necessário seu empenho na retomada dos patrimônios que o governo imperial havia se apossado, bem como imperativa a definição de uma moldura organizacional singular em condições de garantir sua autonomia material, financeira, institucional e doutrinária, capaz de respaldar suas pretensões futuras (MICELI, 2009). Uma das maneiras utilizadas pela Igreja para definir a sua moldura organizacional foi estabelecida dentro de uma perspectiva que propunha alcançar maior expansão territorial em um país de dimensão continental. Foram utilizadas as capitais do Estado para fundar dioceses, ao mesmo tempo em 
que se investiu na atualização dos vínculos administrativos com o poder central estabelecido em Roma. Era necessário que o crescimento de suas estruturas fosse acompanhado por um esforço de disciplinamento do clero e por novos investimentos na formação de seminaristas. Segundo Dias (1996), todo esse esforço se fez por meio de um tratamento atento em relação à importância da doutrina em sua fidelidade com o centro eclesial, ao mesmo tempo, atentou-se para o estabelecimento de modos próprios de instituição da autoridade sob o princípio da unidade.

A administração das dioceses se deu a partir de nomeações internas de padres que se tornaram bispos e também com a ajuda de católicos leigos que aceitavam o trabalho a partir de trocas de favores. A tarefa de organização da Igreja Católica no Brasil se viu diante de uma realidade social marcada por desigualdades extremas entre as regiões e por ampla carência de sustentação das famílias enquanto condição de construção de comunidades. A Igreja dependia de um tratamento especial dado à família para organizar minimamente o sentido de comunidade, suas práticas de culto e a fidelidade aos preceitos emanados da fé.

As trocas de favores também se davam entre muitos bispos e diversos políticos instalados em territórios de poder, com seus modos oligárquicos de exercício do mando sobre as populações e de zelo atento com as alterações possíveis na cultura. Essas informações nos ajudam a compreender porque as grandes festividades promovidas pelo calendário religioso coordenadas pela hierarquia da Igreja para conferir na fé um plano de visibilidade - são de grande serventia, visto que funcionam como uma espécie de palco para os políticos retirarem desses momentos seus ganhos de legitimidade frente a multidões pobres e desorientadas (MICELI, 2009). A religiosidade católica e as formas mais conservadoras do exercício político se manifestam em vários momentos de nossa história em forma de conluios, de conchavos e de conciliações de interesses muito distantes daquilo que legitimaria uma prática religiosa por uma doutrina emanada da fidelidade ao Evangelho. Nesses momentos, somos levados a pensar que, quando os interesses se acirram, a doutrina se estilhaça. O Evangelho não se coaduna com os mandos dos coronéis em nossa terra, a não ser que se deixe trair em sua condição de doutrina e 
expressão de uma tradição milenar. Neste caso, podemos até indagar o quanto uma dinâmica de poder se fortalece por meio de uma forma de traição e se impõe no lugar desta.

Frente às novas modalidades das alianças entre a Igreja e o Estado, já no período republicano, os mandatários puderam recuperar gradativamente, ainda que com muita precariedade, o poder político no país. O Estado, por sua vez, se aproveitou da Igreja para atrair a juventude para os alistamentos dos serviços militares, ao mesmo tempo, utilizou-se da áurea de poder investida na pessoa do bispo, que, em sua figura religiosa, contribuiu para fortalecer os líderes políticos diante do povo.

Esse campo de nova expansão organizativa da vida política fez com que outra grande necessidade para o progresso do país se apresentasse: a educação. Tanto os esforços de organização da Igreja quanto os trabalhos de estruturação do Estado esbarravam nas carências expressivas dessa área. A condição cultural do povo contribuía para a falta de lideranças para ocupar possíveis cargos de gestão e impunha limites no âmbito da cooperação por parte do cidadão. Um programa educacional deveria, portanto, se apresentar para cumprir essa função urgente: a formação de novas lideranças.

Segundo Miceli (2009, p. 29), “A criação de escolas secundárias, femininas e masculinas, se tornara um dos principais itens dos programas de governo dos dirigentes oligárquicos, inclusive nos estados mais atrasados". O Estado não tinha mão de obra qualificada e nem condições financeiras para colocar em prática qualquer política pública mais ambiciosa e, por isso mesmo, colocava a Educação nas mãos da Igreja. Neste contexto, as congregações religiosas dedicadas ao ensino encontravam uma demanda favorável de instalação nas regiões mais estratégicas do país.

A Igreja, por sua vez, assumia a Educação do país em troca de bens materiais e de condições vantajosas, as quais ajudariam a instituição na ampliação de seus poderes e em suas relações com o território e com a população. Havia uma relação de ajuda mútua e uma estratégia de cooperação entre os dois modos de exercício do poder e de liderança.

Uma das estratégias utilizadas pela Igreja foi convidar congregações religiosas, formadas Periódico Horizontes - USF - Itatiba, SP-Brasil - e019006 
na Europa, para se estabelecerem no país, inclusive como parte de um amplo movimento migratório. Essas organizações de homens e mulheres, todos motivados pela fé, tinham experiências com o trabalho comunitário em diferentes meios nas suas sociedades de origem, atuando em hospitais, orfanatos, asilos e colégios.

\section{O movimento internacional de reforma da educação: as intenções declaradas}

As declarações internacionais realizadas no movimento de educação para todos, com o status de pacto e acordo entre países, nos oferecem amplo material discursivo, o qual é suficiente para configurar uma amostragem da dinâmica dos sentidos com caráter de orientação e de sustentação em termos de uma missão. As leituras desses documentos oriundas desta tese foram realizadas com o objetivo de desenhar as paisagens emergentes nas celebrações e nos seus efeitos.

A nossa amostragem se faz com a seleção de três documentos, sem a preocupação de alcançar um levantamento exaustivo, pois qualquer recorte, por menor que seja, contém os elementos principais dos propósitos celebrados nesse tom de campanha internacional, em que certo revestimento de pompa encobre aspectos de vontade de missão. Fizemos a seleção dos seguintes documentos: Declaração Mundial sobre Educação para Todos: satisfação das necessidades básicas de aprendizagem, realizada em Jomtien, no ano de 1990. Declaração de Nova Delhi sobre Educação para Todos, realizada no dia 06 de dezembro de 1993. Declaração de Dakar: Educação para Todos, realizada em Dakar, Senegal, nos dias 26 a 28 de abril de 2000.

Nosso trabalho de cartógrafo consistiu em rastrear nesses textos as marcas capazes de nos apresentar o desenho das paisagens dos sentidos próprios de uma missão internacional com os propósitos educativos. O caráter internacional da dinâmica do poder observado nos textos tem a sua ênfase assentada em uma lógica de mundialização do capital claramente articulado com o empenho de implantação de uma nova racionalidade. O enfrentamento, aqui, tem seu 
ponto de cruzamento entre o Estado e o mercado.

Enfim, os dois trânsitos anteriores nos colocam em contato com os territórios da cultura e do Estado em seus enfrentamentos com o mercado. A justificativa para as nossas escolhas reside no fato de identificarmos as denúncias da crise educacional, seguidas das indicações do tratamento mais adequado aos problemas elencados. Tais indicações têm sua origem em setores do mercado preocupados com aspectos de conflitos e tensões, identificados no seio das sociedades. Agrega a este aspecto o elemento de solução na ênfase dada para a aplicação de tecnologias de comunicação, de informação e de circulação de conhecimentos. Esperou-se fazer um tratamento adequado dos propósitos de aplicação de tecnologia, nos associando aos formuladores das críticas de pedagogias restritas ao campo da aprendizagem. Quando afirmamos a necessidade de um projeto pedagógico além do capital, superamos a crença na aprendizagem isolada de uma preocupação de humanização mais ampla.

A “Declaração Mundial sobre Educação para Todos: satisfação das necessidades básicas de aprendizagem" foi aprovada pela Conferência Mundial sobre Educação para Todos, em Jomtien, na Tailândia, de 5 a 9 de março de 1990. Em seu preâmbulo, encontramos a lógica de uma ideologia fundamentada na economia mundial, quando se afirma que:

[...] ao mesmo tempo, o mundo tem que enfrentar um quadro sombrio de problemas, entre os quais: aumento da dívida de muitos países, a ameaça de estagnação e decadências econômicas, o rápido aumento da população, as diferenças econômicas crescentes entre as nações e dentro delas, a guerra, a ocupação, as lutas civis, a violência [...] (1990, p.1).

Dessa forma, constatamos a presença de uma crise que aumenta significativamente a cada década, pois a educação é utilizada para a busca por resoluções de problemas encontrados na economia, ou seja, o foco pedagógico principal na contemporaneidade consiste em dar condições para que os alunos, que serão os futuros consumidores em potencial, se tornem cada vez mais objetos que alimentam o mercado, transformando-se em consumistas e em adultos preparados para o mercado de trabalho.

Periódico Horizontes - USF - Itatiba, SP-Brasil - e019006 
Desse modo, a educação contemporânea está pautada em uma lógica em que os valores utilizados não são mais aqueles relacionados aos esforços para a construção de sentidos para uma educação humanizante e humanizadora, em diálogo com os próprios homens e com o ambiente que os cerca. A lógica está pautada em palavras-chave, como produção, mercado, capital, tecnologia, competição e tantas outras voltadas a este campo.

Dessa forma, as instituições tornam-se, cada vez mais, empresas que têm como objetivo preparar seus alunos unicamente para o mercado, seja ele de trabalho ou de consumo. Esses programas excluem as outras possibilidades de educação para a busca da eficácia das próprias instituições. Os alunos inseridos nessa lógica não possuem a consciência de que são aprisionados em um mundo doentio, que tem como objetivo capturar os seus corpos e deixá-los cada vez mais doentes.

Essa lógica, cada vez mais impregnada na educação contemporânea, produz o projeto político pedagógico das instituições escolares, as quais se utilizam de conceitos chave, como habilidades e competências, tecnologia, produção de conhecimento, entre outros conceitos, os quais constroem a ação da educação dessas mesmas instituições. Diante desse cenário, elas se julgam como instituições preparadas para dar condições de formação para os filhos de pais que buscam dar a melhor qualidade de ensino, isso porque, quanto mais a escola estiver preparada para dar condições que busquem os melhores rankings, melhor avaliada é a instituição. Sendo assim, as escolas que, antes, tinham como objetivo principal os valores humanos para a formação qualitativa de seus alunos e do mundo, buscam, num segundo momento, através de outros valores, a possibilidade de serem um número em destaque nas avaliações externas, as quais também estão relacionadas a essa mesma lógica de mercado.

Dessa forma, as instituições escolares buscam recursos que as auxiliam em se firmar nessa lógica neoliberal. Procuram, assim, capacitar sua estrutura com salas tecnológicas, softwares de última geração, que, aliás, possuem um curto espaço de vida útil no mercado, pois as empresas tecnológicas lançam diariamente novos produtos. Nesse mesmo sentido, são adotados os celulares e os tablets, que possuem aplicativos que possibilitam aos professores 
incluírem atividades para que seus alunos as desenvolvam. Desse modo, é necessário lembrar que os próprios professores recebem cursos de capacitação para sobreviver ao mundo tecnológico, e caso o professor tenha dificuldades no manejo da máquina, pode vir a perder o seu emprego. Outro recurso tecnológico utilizado pelas escolas para conquistarem pais e alunos são as salas equipadas com lousas digitais, retroprojetores, entre outros objetos. Tudo isso é oferecido desde as idades iniciais, mostrando que as instituições estão cada vez mais atentas às novidades tecnológicas.

Os conteúdos das matérias estão relacionados ao que é cobrado nas avaliações exteriores e não relacionados ao conhecimento que possibilite aos alunos se preparar para estarem no mundo. $\mathrm{O}$ projeto pedagógico da escola tem que responder à construção de habilidades $\mathrm{e}$ competências que possibilitem aos seus alunos ingressarem nas melhores universidades, as quais são capturadas pela mesma lógica. Muitas instituições atentas ao mercado educacional vendem apostilas, métodos pedagógicos, palestras, entre outras atividades. Elas estão preocupadas apenas em atender ao quesito conteúdo, os quais, por sua vez, são resultados de um trabalho de pesquisa sobre o que é cobrados pelas instituições que produzem as avaliações exteriores.

Essa declaração reafirma o compromisso dos países assinantes, celebrado no ano de 1990, de atender as chamadas necessidades básicas de aprendizagem, por meio de uma perspectiva clara de ampliação de oportunidades ao lado de uma manifestação de preocupação com o crescimento populacional:

[...] reiteramos por esta Declaração nosso compromisso de buscar com zelo e determinação as metas definidas pela Conferência Mundial sobre Educação para Todos e pela Cúpula Mundial da Criança, realizadas em 1990, de atender às necessidades básicas de aprendizagem de todos os nossos povos tornando universal a educação básica e ampliando as oportunidades de aprendizagem para crianças, jovens e adultos. Assim fazemos com consciência plena que nossos países abrigam mais do que a metade da população mundial e que o sucesso de nossos esforços é crucial à obtenção da meta global de educação para todos [...] (DECLARAÇÃO DE NOVA DELHI). 
Os organismos responsáveis e as áreas de formulação de políticas públicas recebem, no documento, um tratamento ampliado. Esse esforço não compete apenas ao Estado, pois demanda ações provenientes da família e da comunidade. A educação não pode atuar de forma isolada de outros programas de políticas públicas e, aqui, de forma mais explícita, ela está vinculada à área da saúde.

[...] os programas educacionais bem sucedidos exigem ações complementares e convergentes, no contexto do papel da família e da comunidade, nas áreas de nutrição adequada, cuidados efetivos da saúde e cuidado e desenvolvimento apropriado para crianças pequenas [...] (DECLARAÇÃO DE NOVA DELHI).

Ao afirmar a importância sobre a participação de todos, o documento enfatiza o papel das mulheres reconhecendo que a eficácia do desenvolvimento econômico depende da efetiva inclusão dessa parcela da população na sociedade:

[...] a educação e a incorporação plena de mulheres jovens e adultas à sociedade são metas importantes em si e elementos chaves do processo de desenvolvimento do bem-estar social, da educação de gerações presentes e futuras e da diversificação das opções disponíveis à mulher para o desenvolvimento de todo o seu potencial [...] (DECLARAÇÃO DE NOVA DELHI).

O campo dos reconhecimentos insiste no problema do crescimento populacional como uma preocupação relacionada com as metas do crescimento econômico e faz um apelo para que a educação opere como um instrumento de cooperação nesse contexto. A participação de todos os cidadãos é, assim, compreendida como uma repartição do peso que esse desafio representa para a sociedade.

A reunião de Dakar emitiu um documento afirmando o compromisso com a "Educação para todos" como um desafio para o Estado e para a sociedade a partir do reconhecimento de que as metas assumidas em reuniões anteriores revelavam resultados questionáveis. Há uma 
afirmação do crescimento quantitativo com relativo grau de atendimento dos propósitos, mas não há uma confirmação em relação à qualidade da educação que vem sendo realizada. Não podemos perder de vista que o documento foi publicado sob a chancela da UNESCO, que, enquanto organismo das Nações Unidas, carrega uma autoridade capaz de conclamar os Estados para assumir em suas Constituições ao menos o espírito de preocupação com uma educação universalizada no âmbito de toda a sociedade. Essa modalidade de reunião envolve a participação de enviados oficiais dos Estados e acarreta uma rede de ações por parte de organismos da sociedade civil, mas, do ponto de vista de um olhar atento para o campo da ideologia, cabe ressaltar que a divulgação do documento, resultado da reunião de Dakar, contou com o apoio da Fundação Ford, fato que nos alerta sobre a importância de uma atenção para tensões e contradições inerentes aos atos de proclamação de compromissos. Não se trata de assumir uma aversão diante das investidas do mercado, e, sim, de manter os sentidos em alerta sobre as tensões inerentes aos documentos e aos acontecimentos. Aqueles operam na garantia das estruturas que articulam esforços dos Estados em cooperação com a sociedade. Já os acontecimentos nos obrigam a olhar para uma dinâmica de cultura que se apresenta com materialidade própria, com lastro social de longa data. As espacialidades dos organismos também se confrontam com as temporalidades da cultura.

Na retomada do Documento de Dakar, recolhemos as metas assumidas enquanto compromisso dos povos com uma educação para todos. Observamos nas metas formuladas aqueles aspectos que nos auxiliam na problematização de um movimento de constituição do educador ao lado da elaboração do projeto pedagógico.

As metas assumidas pelo movimento da educação para todos estão inseridas em um campo de afirmação dos direitos. Novamente, há uma vinculação do gesto de compromisso com algo mais amplo, situado na Declaração Universal dos Direitos Humanos. Nesse contexto social de afirmação de direitos, a Educação é afirmada como ação fundamental para o desenvolvimento econômico de uma sociedade, bem como para a garantia de uma convivência em termos de afirmação da democracia. A esfera da economia, configurada nos termos de 
desenvolvimento, está articulada com a política enquanto afirmação de direitos e garantia de um convívio social menos bárbaro, portanto, mais saudável. A reunião de Dakar afirma os compromissos da "educação para todos" reconhecendo que suas metas não vêm sendo alcançadas desde o período da assinatura do documento de 1990.

As necessidades básicas de aprendizagem são confirmadas tanto nos instrumentos quanto nos conteúdos, sempre em busca da garantia de desenvolvimento econômico e de ampliação da participação política dos indivíduos. As metas da educação são formuladas como desdobramento operacional para atingir as finalidades citadas.

A primeira meta afirma a necessidade de continuar investindo na expansão do ensino para atingir todas as crianças, de um modo universal, como condição para sair de situações de vulnerabilidade social A segunda meta afirma uma educação de qualidade e destaca uma atenção especial para as meninas. Na terceira meta, a educação de adultos precisa ser aprimorada de forma apropriada para os indivíduos se sustentarem na vida. A quarta meta defende o aumento do nível da alfabetização, sobretudo para as mulheres. A disparidade entre os gêneros deve ser combatida de acordo com a quinta meta. Encontramos, aqui, outra vez, a insistência da importância da participação da mulher. A melhora no nível de alfabetização e o desenvolvimento da capacidade do cálculo e das habilidades essenciais para a vida reforçam a afirmação da educação para assegurar o desenvolvimento da economia.

Para todas as metas serem alcançadas de forma satisfatória, a gestão da educação precisa considerar o valor da participação e assumir os princípios de democracia com capacidade de controle sobre os seus resultados. Essas tarefas não podem ficar restritas ao Estado, pois demandam o envolvimento de todos os setores da sociedade em sua formulação e execução. A escola, portanto, deve se comprometer em criar os ambientes favoráveis para a realização das metas. O nível dos professores deve ser elevado em sua condição moral e profissional. As novas tecnologias de informação e de aprendizagem devem ser utilizadas amplamente para se garantir qualidade nos resultados.

Enfim, observamos como os documentos vêm registrando impasses e dificuldades para Periódico Horizontes - USF - Itatiba, SP-Brasil - e019006 
alcançar as metas de uma real universalização da educação. A "educação para todos" se apresenta como um discurso de legitimação para obter efeitos no que tange à adesão dos Estados, porém não demonstra eficácia em tocar substancialmente a materialidade da dinâmica de cultura, uma vez que se mantém aprisionada aos ditames de um modelo de economia que se mostra divorciado de uma real prática política. Os governantes dos países, ao não deliberarem sobre a efetiva aplicação dos recursos da economia, assinam os documentos e assumem os fracassos dos resultados.

\section{A educação desenvolvida pela Rede Filhas de Jesus}

A Congregação Religiosa das Filhas de Jesus, ao se instalar em Pirenópolis, Estado de Goiás, tinha como objetivo fundar um colégio para educar e catequizar as filhas dos fazendeiros, comerciantes e profissionais liberais da cidade. A educação oferecida pelas escolas confessionais católicas, assentadas em uma concepção pedagógica de inspiração advinda dos Padres Jesuítas, inspirava a confiança das elites locais. Os senhores de terra esperavam por uma educação a serviço daquele modelo de ordenamento social em conciliação com os seus interesses.

Cabe ressaltar, aqui, que o serviço educacional oferecido por uma congregação religiosa, constitutivo do nosso objeto de estudo, tem inspiração na espiritualidade forjada no amplo movimento de Santo Inácio de Loyola. Recolhemos os seus documentos de caráter doutrinário e pedagógico, para, a partir deles, examinarmos uma trajetória de missão evangelizadora articulada com o trabalho educacional. Em nosso estudo, foi possível realizar um trabalho de verificação dos documentos em que parte dessa experiência está registrada. Neste exercício, rastreamos as marcas dos problemas relacionados com a expansão da obra religiosa bem como algumas dificuldades que emergiram das articulações entre as suas práticas educativas e os rituais religiosos no contexto da consolidação da República Brasileira.

A Congregação Religiosa "Filhas de Jesus", de origem espanhola, foi fundada no ano de 1871, na cidade de Salamanca. Segundo Tomero (1990) sua fundadora se chamava Joana Josefa. 
Após a fundação de sua obra, ela alterou o seu nome e passou a se chamar Madre Cândida Maria de Jesus. De origem humilde, era filha de João Miguel Cipitria, tecelão, e de Maria Jesus Barriola, dona de casa. Teve três irmãs: Maria Del Carmen, Francisca Sotera e Maria Dominica.

No Brasil, no ano de 1911, na cidade de Pirenópolis, essa congregação fundou o seu primeiro colégio, que encerrou as suas atividades em 1926. Em 1912, um grupo advindo da Espanha foi morar na cidade de Mogi Mirim. Em 1913, uma nova obra foi aberta em Caconde, com encerramento logo em seguida, em 1915. Muitas novas obras se sucederam em diversas cidades de nosso país, como nos mostra a seguinte lista: em 1915, em Bragança Paulista; em 1916, em Belo Horizonte; em 1918, em Leopoldina; em 1929, em Santos Dumont com o encerramento realizado em 1940. Em 1932, foi inaugurado um colégio em Mar de Espanha, o qual teve o seu fechamento em 1933. Em 1935, inaugurou-se a obra do Rio de Janeiro e, em 1952, na cidade de Campinas. Em 1966, essas missionárias chegaram em Apucarana. Nessas diversas localidades, as irmãs iniciavam seus trabalhos missionários sempre por meio da fundação de seus colégios, oferecendo os serviços religiosos e educacionais para as elites locais.

Desde a inauguração da primeira obra até os dias atuais, essa rede de colégios tem como texto de direção de sua ação educacional, documentos da Igreja e de sua fundadora que com o passar dos anos, esse conjunto de excertos se transformou em um documento chamado de "Nosso Modo Próprio de Educar - NMPE". O regimento das escolas usa esse texto como referência, pois é um documento de orientação pedagógica para toda a rede internacional. 0 fato do texto se apresentar como uma expressão da tradição religiosa nos faz assumi-lo, neste estudo, como o principal documento de apoio desta tese. Mais do que representar um texto pedagógico estritamente técnico para os fins utilitários de organização do cotidiano escolar, encontra-se nele uma ampla concepção, com claros vínculos doutrinários, na qual está presente uma dimensão de tradição suficientemente sólida para cumprir o papel de orientar a ação de todos os seus educadores e de sustentar a responsabilidade exigida pela obra pedagógica.

O Projeto Político Pedagógico da rede de ensino Filhas de Jesus foi idealizado por Madre Cândida, no final do século XIX, período em que os valores liberais se estruturavam por toda a 
Espanha e, consequentemente, se chocavam com os valores religiosos prescritos pela Igreja. Com o liberalismo, a sociedade começou a ser organizada, desvinculando os valores e dogmas da Igreja, consequentemente, o núcleo familiar passou por transformações bem como o papel da mulher. A Igreja se organizava por meio de alianças com alguns líderes políticos espalhados pelo país e iniciou fundações de congregações religiosas que se especializaram em diversas áreas, como a social, de saúde, de educação, entre outras, formando uma espécie de batalhão que se preparava para lutar, ideologicamente, contra os políticos liberais. Precisamente neste período, Madre Cândida, com a ajuda do Padre Herranz, fundou uma congregação religiosa feminina, com o objetivo de educar, por meio dos valores evangélicos e dogmáticos idealizados pelos líderes da Igreja Católica, principalmente, as mulheres de classes abastadas, entretanto, as menos abastadas também foram educadas, porém, em menor número. A congregação educou crianças e jovens através da fé, dos dogmas e dos valores evangélicos, concomitantemente, os ensinou a ler, a escrever, a contar e a realizar trabalhos manuais, para que se tornassem mães de família exemplares assim como componentes de congregações religiosas.

A evangelização é o espírito principal da missão de ensinar da congregação, de anunciar o reino de Deus e de atender às necessidades do educando e da comunidade em que está inserida. O trabalho educativo visa às relações interpessoais, baseadas no respeito, na solidariedade, no amor e no serviço, fazendo com que seus membros se sintam parte de uma comunidade humana em que todos são importantes para a construção do reino. A educação elaborada pela congregação está fundamentada em dois pressupostos, a glória de Deus e o bem do próximo e o serviço da Igreja.

A glória de Deus e o bem do próximo é uma atitude básica, uma constante na vida de Madre Cândida, ela é uma meta para quem trabalha na rede de ensino. Na introdução do documento NMPE - "Nosso Modo Próprio de Educar", a glória de Deus e o bem ao próximo estão relacionados com o sentido de que o homem viva e, dessa maneira, se expresse, buscando, sempre, tornar-se, um homem novo em Cristo e, dessa maneira, expressando e concretizando a glória de Deus. Sendo assim, educar cristãmente é a expressão concreta que a congregação busca 
em ajudar o próximo a estar com Deus.

O serviço voltado à Igreja é o segundo da educação desenvolvida pelas Filhas de Jesus, pois a Igreja dá continuidade ao papel de Cristo, buscando o desenvolvimento integral da pessoa, sempre numa perspectiva evangélica. O discernimento é um modo de proceder na educação idealizada pela fundadora. Ela está pautada na análise do que agrada a Deus, ponderando sob o guia do Espírito. Diante desses aspectos, a educação proposta pelas Filhas de Jesus busca corresponder às necessidades da própria Igreja, por meio da fidelidade do carisma e da escuta aos apelos mais urgentes dos diferentes contextos da Congregação.

Dessa maneira, a finalidade da ação educativa da congregação se pauta em três aspectos. O primeiro deles consiste no desenvolvimento integral da pessoa, quesito em que o serviço apostólico tem como objetivos salvar o próximo e fazê-lo alcançar a perfeição, educando-o cristãmente, por meio de uma ótica individual e cristã. O segundo aspecto consiste na prioridade da educação na fé, quesito que consiste em uma educação por meio da fé e na adesão da mensagem de Jesus Cristo. A educação se concretiza na concepção cristã da pessoa, da vida e do mundo: "A fé é apresentada como uma opção pessoal, livre e consciente, vivida em comunidade e projetada para a sociedade o testemunho e o compromisso" (parte do artigo 11 do documento NMPE). Finalmente, o terceiro aspecto que compõe a finalidade da ação educativa da congregação são os membros úteis na Igreja e na Sociedade. Busca-se a dimensão comunitária dada por Deus à pessoa humana, integrante de uma sociedade pela qual é corresponsável. A ação educativa manifesta-se sempre no sentido e no valor comunitário. Acredita-se que o ser humano é dotado de uma força interior dinâmica e possível de transformação, que o meio em que ele está inserido o ajuda em sua evolução enquanto pessoa que vive em comunidade. Ao mesmo tempo, ele é um ser único e possui habilidades pessoais a serviço de um bem maior.

No artigo 72 do documento "Nosso Modo Próprio de Educar", encontramos a afirmação de que: "[...] o mundo é visto como comunidade, uma grande família humana em que se insere Jesus, homens e mulheres, irmãos e filhos de Deus, criados à sua imagem e semelhança e compartindo todos os mesmos direitos e possibilidades" (NMPE, Art. 72, 1994, p.31). Neste 
artigo, percebemos que o projeto político pedagógico da rede de ensino leva aqueles que estão, de alguma forma, ligados à congregação a terem a percepção de que são membro de uma comunidade, são parte de um todo, o que, consequentemente, os faz assumir uma corresponsabilidade diante do mundo em que estão inseridos, bem como os levam à construção de uma relação positiva com o outro, pois a ligação parental existente entre os indivíduos possibilita a criação de um ambiente de aproximação, de respeito e de amor ao próximo.

A visão de mundo do projeto político pedagógico da rede está inspirada na espiritualidade inaciana que a fundadora assumiu. O mundo é um dom de Deus, que como Pai, nos oferece para que todos o habitemos. E todas as coisas sobre a terra foram criadas por Ele, com uma finalidade que é preciso respeitar (NMPE, art.69). Esse artigo nos mostra que Deus - e não os homens - é o dono do mundo. Os homens podem, apenas, usufruir dele comunitariamente, o que impede, assim, que se sintam donos e que façam o que quiserem no mundo. Essa concepção vem reforçar que todos têm os mesmos direitos e os mesmos deveres no que tange ao cuidado do mundo. $O$ respeito pelo planeta é imprescindível, bem como cuidar do bem comum e se sentir dele a partir de uma perspectiva coletiva, assim busca-se educar os alunos no espírito de comunidade, da fraternidade e do respeito perante as pessoas e o mundo.

A revelação de Deus está em todo o lugar e tempo: "Ele está em todas as coisas e as pessoas, na história, através dos sinais de cada lugar e de cada tempo, por isso, ele deve ser procurado e encontrado" e segue: " [...] no entanto, esse mundo está atingido pelo pecado, pelo engano, pela falsidade e a injustiça; pelas divisões entre as pessoas, pela exploração descontrolada e pela agressão ao meio ambiente". Nos dois artigos supracitados, ambos complementares, podemos perceber que o transcendental configura essa visão do mundo, funcionando como uma das "armas" utilizadas pela Igreja, no sentido de buscar compreender o mundo através do inexplicável, vendo-o e sentindo-o. Mesmo se utilizando do racionalismo para construir maneiras de reestruturar a instituição, a Igreja, por sua vez, busca na revelação e na fé métodos para convencer o povo a respeito de seus valores e dogmas.

Ainda em relação ao mundo, no artigo 72, lemos: 


\begin{abstract}
Através do trabalho educativo, a Congregação deseja colaborar na formação de cristãos, empenhados em cooperar com Deus em sua ação cooperadora e que contribuam para melhorar as relações homens-natureza. Pretende, do mesmo modo, ajudá-los a viverem coerentemente sua fé, testemunhando os valores evangélicos na sociedade pluralista. Pretende ajudá-los para que em sua própria vocação comprometam a vida na transformação de situações e estruturas de pecado; para que colaborem na construção de um mundo mais solidário e fraterno, de acordo com o projeto salvador do Pai (NMPE, Art. 72, 1994, p. 31).
\end{abstract}

A congregação se coloca como um instrumento da Igreja que se mantêm inserido em uma sociedade pluralista e cheia de pecados. Sendo assim, busca-se por transformações que serão utilizadas pela educação para afastar o homem do sofrimento e da distância de Deus. A educação idealizada por Madre Cândida busca a promoção da defesa da vida humana, o cuidado com o meio ambiente, o respeito e a conservação da natureza, a responsabilidade no uso de tudo o que é posto ao serviço comum e a abertura à intercomunicação mundial. Entende-se que estamos inseridos em uma realidade pluricultural e dinâmica, em que diversas culturas se influenciam na busca de valores e de sentido de vida. Nesse sentido, a educação das Filhas de Jesus objetiva promover um diálogo entre fé e cultura.

No artigo 92 do "Nosso Modo Próprio de Educar", a cultura é entendida como atitude global ante à vida, abrangendo saber e valores, conhecimentos e habilidades, instituições e costumes de um grupo humano. No artigo 93, a fé está relacionada ao cristão, que tem um sentido duplo: 1) evangelizar a cultura, ou seja, introduzir nela o evangelho de Jesus, descobrindo nela as pegadas de Jesus, ampliando horizontes até a dimensão transcendente, bem como denunciar os contra-valores vigentes na sociedade e a pretensão da cultura de ser autossuficiente para o homem; 2) inculturar a fé, de modo a prestar atenção especial aos desafios lançados a ela pela cultura e expressar-se através de moldes culturais, introduzindo pautas de discernimentos e valorização.

A educação das Filhas de Jesus tem como base os valores evangélicos enquanto construção de mundo. As pessoas que se propõem a participar da ação educativa elaborada pela 
congregação devem estar dispostas à promoção da glória de Deus e à promoção do bem do próximo, abrindo-se incondicionalmente aos lugares e destinatários focos da ação educativa. Isso significa que a pessoa que quiser fazer parte da ação educativa das Filhas de Jesus deve estar aberta ao local onde será enviada e jamais escolherá o tipo de trabalho que irá desenvolver. Essa realidade é designada apenas às mulheres da própria congregação e é pautada por três critérios.

O primeiro deles é o universalismo. O serviço educativo é prestado em qualquer ponto geográfico e destinado a qualquer pessoa ou grupo, sem distinção de raça, cultura, condição social, idade, sexo, religião, entre outros aspectos. A entrada e a permanência das Filhas de Jesus no Brasil estão pautadas neste critério do universalismo. Para que a escolha, a ação e envio aconteçam, é imprescindível o discernimento em relação às necessidades do local e da própria congregação. O segundo critério consiste na maior necessidade, ou seja, busca-se atender, em primeiro lugar, àqueles que apresentam uma maior necessidade no campo da educação cristã. Existe, ainda, um terceiro item, intitulado outros critérios, o qual é dividido em alguns subitens. As Filhas de Jesus podem escolher as obras e atividades das quais se espera conseguir maior fruto no campo da educação cristã. Elas podem prestar seu serviço, estando em igualdade de condições às pessoas ou aos grupos que tenham oferecido uma ajuda especial, sempre com sentido de gratidão. Independente do lugar em que a ação educativa aconteça, se deve atender prioritariamente as pessoas que podem estender o bem a muitas outras.

Os meios que a rede de ensino Filhas de Jesus utiliza para a concretização da ação pedagógica estão fundamentados na catequese e na educação integral dos alunos nas escolas espalhadas em 18 países. No artigo 26 do documento NMPE, encontramos o que a congregação entende por catequese:

Entendemos por catequese, o processo com que se pretende promover a maturação da fé inicial: educar o seguidor de Jesus por meio de um conhecimento mais profundo e sistemático de sua pessoa e de sua mensagem. Levá-lo a uma experiência de vida cristã mais plena e comprometida. Este trabalho catequético fica situado no conjunto de nossa ação pastoral, que procura despertar a aceitação da mensagem evangélica como realidade

Periódico Horizontes - USF - Itatiba, SP-Brasil - e019006 
salvífica. E, em relação a ela, procura também promover em quem recebe assim a mensagem, uma maturação espiritual, uma experiência litúrgica e no serviço aos mais necessitados. 0 primeiro anúncio de Jesus e sua mensagem - que precede a catequese em sentido estrito - constitui uma atividade pastoral básica, à que damos preferência quando desempenhamos nosso trabalho educativo entre os não-cristãos (NMPE, Art. 26, 1994, p. 31).

A ação catequética busca uma educação humanizadora e humanizante, em que a educação moral é elaborada e desenvolvida aos moldes dos valores evangélicos, de maneira individual e comunitária. A relação entre os alunos e entre os demais membros da comunidade é constituída a partir do respeito ao próximo e da busca por um bem comum.

No artigo 31 do NMPE, encontramos o que a rede de ensino entende por educação integral cristã:

Por educação integral cristã, entendemos um processo orientado ao desenvolvimento da personalidade em todas as suas dimensões, em que cada educando chegue a adquirir uma visão cristã do mundo e da vida. Essa aquisição deve fazer-se mediante a assimilação crítica e sistemática da cultura, em harmonia com a fé. E deve capacitar à pessoa a melhor comprometer-se com a história de seu tempo (NMPE, Art. 31, 1994, p. 17).

O processo pedagógico das Filhas de Jesus vai além da instrução dos alunos, ele busca, também, uma promoção cultural e humana de adultos que se prontifiquem a transformar este mundo egoísta, desigual e desumano, tendo Jesus como referência, tanto em questões individuais quanto comunitárias.

Na transmissão da mensagem cristã, ocupa um lugar central a imagem de Deus. O artigo 45 do NMPE fala que o tipo de relação que com Ele se faz surgir é o comportamento existencial que deriva de sua aceitação na própria vida, mais concretamente, na adesão à pessoa de Jesus como resposta a seu chamado. Nesse artigo, percebemos que a congregação busca educar através da transmissão da mensagem cristã e por meio do comportamento das pessoas que estão engajadas na maneira de se fazer educador, buscando, assim, materializar uma educação 
evangelizante e evangelizadora.

De acordo com os artigos 46 a 49 do NMPE, a educação se fundamenta em um Deus absoluto, grande e poderoso que, antes de tudo é o Pai que criou o mundo para todos, que quer nosso bem, nossa felicidade e nossa salvação, que nos compreende e nos perdoa. Ele espera porque é a bondade e a misericórdia infinita, o amor sem limites, um pai que cuida de todos, que é força e esperança para os fracos e que a todos faz irmãos. Ele é próximo, se dá ao outro gratuitamente e está presente em qualquer acontecimento. Toda essa proximidade de Deus se concentra na pessoa de Jesus, a qual que veio até nós, até a nossa terra e a nossa história. É em Jesus que vemos Deus, Jesus é o instrumento que nos leva até Deus, materializando o amor de Deus em cada um de nós. Jesus, que sempre foi obediente e fiel ao querer do Pai, assumiu sua missão até o fim, viveu seu amor por Ele e por nós e morreu carregando nossos males e pecados, no entanto, vive em nós e entre nós, particularmente, nos fracos. Deus envia o Espírito, que é luz para a mente, amor no coração, fortaleza e graça no sofrimento e no trabalho pela extensão do reino. É neste Espírito que a Igreja se constrói e se santifica, bem como continua atuando e nos interpelando sobre as necessidades de nosso mundo.

\section{Considerações Finais}

O esforço por fazer um desenho de paisagens no movimento dos sentidos fez com que percebêssemos o quanto a educação elaborada pela rede Filhas de Jesus vai além dos modelos neoliberais e que ainda persiste em buscar por uma educação humanista religioso, ao qual é preciso uma formação continua para seus professores que tem como missão, aplicar o projeto político pedagógico ao qual está inserido e mais, para que o projeto pedagógico tenha sucesso, também é preciso que todos acreditem nele para que consigam desenvolver um bom trabalho e alcancem seus objetivos.

\section{Referências}

Periódico Horizontes - USF - Itatiba, SP-Brasil - e019006 
ACCYOLI, G. Carlos Oswald: uma história e dois temas. Pro-posições, Campinas, v. 28 no 03, p.60-82. Set/Dez, 2017.

ARDUINI, G. R. A Igreja Católica e suas instituições de Ensino Superior. Pro-posições, Campinas, v. 28 no 03, p.60-82. Set/Dez, 2017.

BITTENCOURT, A. B. A era das congregações - pensamento social, educação e catolicismo. Proposições, Campinas, v. 28 no 03, p.29-59. Set/Dez, 2017.

BONATO, M. A Igreja Católica e as experimentações pastorais e missionárias na década de 1960: a experiência de Gioventù Studentesca no Brasil. Pro-posições, Campinas, v. 28 no 03, p.112-143. Set/Dez, 2017.

BRITO, A.X. Orar, ensinar ou agir. As diversas formas de cumprir o Carisma de Sion. Proposições, Campinas, v. 28 no 03, p.112-143. Set/Dez, 2017.

COLOMBO, M.A.C. As congregações religiosas femininas francesas frente às opções de Secularização ou Exílio na França da Terceira República. Pro-posições, Campinas, v. 28 no 03, p.169-203. Set/Dez, 2017.

CUSTÓDIO, M. A. O papel da Congregação das Capuchinhas na formação de classes médias e elites regionais. Pro-posições, Campinas, v. 28 no 03, p.169-203. Set/Dez, 2017.

DIAS, Romualdo. Imagens de ordem: a doutrina católica sobre a autoridade no Brasil: 19221933. 1a ed. São Paulo: Editora UNESP, 1996.

MICELI, S. A elite eclesiástica brasileira: 1890-1930. 1a ed. São Paulo, SP: Ed. Companhia das Letras, 2009.

NERIS, W.S; SEIDL, E. Crise e recomposição do habitus religioso na periferia do espaço católico. Pro-posições, Campinas, v. 28 no 03, p. 83-111. Set/Dez, 2017.

CONGREGAÇÃO DAS FILHAS DE JESUS. Nosso Modo Próprio de Educar, 1999.

LEONARDI, P. Associações católicas como instâncias socializadoras e de controle do tempo: o caso do Liceu e do Santuário Sagrado Coração de Jesus. Pro-posições, Campinas, v. 28 no 03, p. 83-111. Set/Dez, 2017. 
ORGANIZAÇÕES DAS NAÇÕES UNIDAS PARA A EDUCAÇÃO, CIÊNCIA E CULTURA - Unesco. Declaração Mundial sobre Educação Para Todos (Conferência de Jomtien). Tailândia: Unesco, 1990. Disponível em: www.unesco.com.br/publicação/doc-internacional. Acesso em: 12 de fevereiro de 2018.

ORGANIZAÇÕES DAS NAÇÕES UNIDAS PARA A EDUCAÇÃO, CIÊNCIA E CULTURA - Unesco. A Declaração de Nova Delhi sobre Educação Para Todos, Nova Delhi- Índia: Unesco, 1993b. Disponível em: www.unesco.com.br/publicação/ declaraNdelhi. Acesso em: 10 ago.2004.

ORGANIZAÇÕES DAS NAÇÕES UNIDAS PARA A EDUCAÇÃO, CIÊNCIA E CULTURA - Unesco. O Marco de Ação de Dakar Educação Para Todos: atendendo nossos Compromissos Coletivos. Dakar, Senegal: Cúpula Mundial de Educação, 2000. Disponível em: www.unesco.com.br/publicação/marcoDakar. Acesso em: 10.fevereiro.2018.

TOMERO, M. C. F. Donde dios te llame: una vida consagrada a la educación cristana, Salamanca, ES: Edicione Sígme, 1990.

Recebido em fevereiro de 2018. Aprovado em agosto de 2018. 